\title{
MOBILE GAME HALMA MULTIPLAYER
}

\author{
Novrido Charibaldi, Wilis Kaswidjanti, Muhammad Dhimas \\ novrido_ch@walla.com \\ Jurusan Teknik Informatika FTI UPN "Veteran" Yogyakarta
}

\begin{abstract}
Handphone besides as a communication tool also has a function as a medium of entertainment. Various multimedia services and communications facilities contained therein, one Bluetooth. Games is one application that always exist in the mobile phone, and with a wider variety of games development by utilizing the services in mobile. In this research, the development of the multiplayer games for mobile phones utilizing Bluetooth communication media using the programming language Java Micro Edition (J2ME). Design method using the grapple, NetBeans IDE 6.1 is used as tools to assist programming.

Keywords : Handphone, Games, Bluetooth, J2ME, GRAPPLE, NetBeans IDE 6.1

Handphone selain sebagai alat komunikasi juga memiliki fungsi sebagai media hiburan. Berbagai layanan multimedia dan sarana komunikasi terdapat di dalamnya, salah satunya Bluetooth. Games merupakan salah satu aplikasi yang selalu ada di dalam handphone, dan dengan perkembangannya games semakin bervariasi dengan memanfaatkan layanan-layanan dalam handphone. Dalam penelitian ini, dilakukan pembuatan multiplayer game untuk handphone memanfaatkan media komunikasi bluetooth menggunakan bahasa pemrograman Java Edisi Micro (J2ME). Metode perancangan menggunakan GRAPPLE, NetBeans IDE 6.1 digunakan sebagai tools untuk membantu pemrograman.

Kata kunci : Handphone, Games, Bluetooth, J2ME, GRAPPLE, NetBeans IDE 6.1
\end{abstract}

\section{PENDAHULUAN}

Teknologi perangkat telekomunikasi sudah maju pesat. Hanphone sebagai alat komunikasi sudah berkembang menjadi perangkat multimedia saat sekarang ini. Dilengkapi dengan layanan-layanan multimedia, seperti layar berwarna, kamera, pemutar musik, games, sebagai media hiburan penggunanya. Media input/output data juga terdapat di dalamnya, salah satunya yaitu Bluetooth.

Kebanyakan orang sudah memiliki handphone sebagai media komunikasi dan media hiburan pribadi. Games sebagai salah satu media hiburan di dalam handphone banyak digemari. Halma merupakan salah satu Game yang interaktif yang dimainkan oleh dua atau tiga pemain.

Tujuan penelitian ini adalah untuk menghasilkan Halma Multiplayer Game yang diaplikasikan pada handphone dengan memanfaatkan perangkat Bluetooth sebagai media penghubung. Game ini dapat dimainkan oleh dua atau tiga pemain dalam satu waktu yang bersamaan, masing-masing pemain menggunakan satu perangkat handphone.

Manfaat dari penelitian ini diharapkan game ini menjadi media hiburan bagi sekelompok orang pengguna handphone untuk bermain game bersama menggunakan handphone masingmasing dalam suatu wilayah yang masih dalam jangkauan perangkat Bluetooth sebagai media penghubung.

\section{TINJAUAN PUSTAKA}

Metodologi yang digunakan untuk membuat permainan ini adalah Guidelines for Rapid APPLication Engineering atau biasa disebut GRAPPLE yang terdiri dari lima segment yaitu Requirement gathering (perencanaan kebutuhan), Analysis (analisis), Design (perancangan), Development (pengembangan), Deployment (penyebaran). Sebelumnya pernah dibuat game Halma multiplayer menggunakan media intranet dan game ini masih diaplikasikan pada komputer oleh Rosalina Permatasari pada tahun 2006 dari Universitas Pembangunan Nasional "Veteran" Yogyakarta.

Perbedaan dari penelitian yang dilakukan oleh Rosalina Permatasari yaitu dalam implementasi dan penerapan aplikasi. Pada penelitian ini, aplikasi dijalankan oleh perangkat handphone berbasis J2ME menggunakan media Bluetooth dan dapat dimainkan oleh dua atau tiga orang, sedangkan aplikasi permainan Halma yang dibuat oleh Rosalina Permatasari 
dibangun menggunakan bahasa pemrograman Microsoft Visual Basic .NET dijalankan komputer dan intranet sebagai media koneksinya.

Kemudian bahasa pemrograman yang digunakan pada penelitian sebelumnya oleh Rosalina Permatasari yaitu, sedangkan pada penelitian ini menggunakan bahasa pemrograman J2ME.

\subsection{Games}

Games atau permainan dalam dunia teknologi informasi sering diartikan sebagai permainan yang menggunakan perangkat digital, seperti game konsol, game di dalam komputer atau perangkat mobile.

\subsection{Mobile Games}

Permainan yang tersimpan dan dimainkan dalam perangkat mobile (handphone, PDA, smartphone). Platform yang berbeda menyebabkan teknologi dan ketersediaan permainan akan berbeda pada tiap perangkat moblie.

\subsection{Halma}

Halma merupakan sebuah permainan papan yang bertujuan untuk memindahkan kepingan halma dengan warna tertentu ke sudut yang berlawanan di depannya. Bentuk papan halma bermacam-macam, yang digunakan pada penelitian ini adalah yang berbentuk segienam. Aturan dasar pada halma yaitu menggerakan kepingan halma selangkah ke tempat kosong di sekitarnya, atau dapat juga melompati keping halma lain jika ada tempat kosong di sekitar kepingan yang dilompati.

\subsection{J2ME}

J2ME merupakan sebuah kombinasi yang terbentuk antara sekumpulan interface Java yang sering disebut dengan Java API (Application Programming Interface) dengan JVM (Java Virtual Machine) yang dirancang khusus untuk perangkat mobile (Budi Raharjo dkk, 2007). J2ME pada dasarnya terdiri dari tiga bagian, yaitu : konfigurasi, profil, dan paket-paket opsional.

\subsubsection{Konfigurasi}

Konfigurasi adalah bagian yang berisi JVM (Java Virtual Machine) dan beberapa library kelas lainnya. JVM yang terdapat di J2ME berbeda dari JVM tradisional yang terdapat pada J2SE. JVM pada J2ME sudah dirancang secara khusus untuk perangkat mobile (Budi Raharjo dkk, 2007).

\subsubsection{Profil}

Profil merupakan bagian dari Konfigurasi, selain sekumpulan kelas yang terdapat pada konfigurasi, terdapat juga kelas-kelas spesifik yang didefinisikan lagi di dalam profil (Budi Raharjo dkk, 2007). Profil akan membantu secara fungsional yaitu dengan menyediakan kelas-kelas yang tidak terdapat pada level konfigurasi. Bagian dari profil yang sering digunakan yaitu MIDP (Mobile Information Device Profile).

\subsubsection{Paket Opsional}

Paket opsional merupakan paket-paket tambahan yang dibutuhkan oleh aplikasi sehingga pada saat proses deployment paket-paket tersebut perlu didistribusikan juga sebagai bagian dari aplikasi bersangkutan. Tidak seperti pada Profil dan Konfigurasi, paket-paket opsional bukan merupakan paket yang dibuat oleh perusahaan alat yang digunakan.

\subsubsection{Siklus Aplikasi J2ME}

Setiap aplikasi J2ME (midlet) senantiasa berada dalam salah satu dari tiga state berikut: Paused, Active, atau Destroyed. Saat constructor dipanggil, maka Midlet akan berada dalam kondisi Paused. Jika method startApp() dipanggil, maka Midlet akan aktif, sebaliknya, jika Midlet menemui method destroyApp(), maka Midlet akan dibuang dari memory (Destroyed). Ketiga method tersebut pasti terdapat pada setiap kelas midlet.

\subsection{Bluetooth}

Bluetooth berfungsi sebagai teknologi komunikasi wireless yang beroperasi dalam pita frekuensi $2.4 \mathrm{GHz}$ unlicensed ISM (Industrial, Scientific and Medical) dengan menggunakan sebuah frequency hopping tranceiver yang mampu menyediakan layanan komunikasi data dan suara secara real-time antara host-host bluetooth dengan jarak jangkauan layanan yang terbatas (Yamta, 2005).

\subsection{UML (Unified Modelling Language)}

UML merupakan suatu bahasa grafis untuk menggambarkan kelompok elemen-elemen untuk menspesifikasi, visualisasi, membangun dan mendokumentasikan baik untuk sistem perangkat lunak maupun model-model bisnis yang non perangkat lunak. Diagram UML yang digunakan dalam penelitian ini yaitu diagram Use Case, diagram Activity, diagram Class, dan diagram Sequence. 


\subsubsection{Diagram Use Case}

Diagram use case adalah diagram yang menggambarkan relasi antara siapa yang mengakses layanan apa dan relasi antara actor dengan actor yang lain. Siapa dinotasikan oleh actor dan layanan dinotasikan oleh use case. Relasi antar actor dinotasikan dengan relasi generalization dan relasi antara actor dengan use case dinotasikan dengan association.

\subsubsection{Diagram Activity}

Diagram activity adalah teknik untuk menggambarkan logika prosedural, proses bisnis dan jalur kerja dalam satu atau lebih use case. Perbedaan prinsip antara diagram activity dan diagram alir adalah diagram ini mendukung perilaku paralel (Munawar, 2005).

2.6.3 Diagram Class

Diagram class adalah diagram yang menggambarkan model struktur dari sistem yang sedang dibangun. Suatu class menunjukkan ciri/attribute dan tingkah laku/method suatu class.

2.6.4 Diagram Sequence

Diagram sequence menjabarkan urutan bagaimana kerjasama terjadi antar class dalam tiap-tiap use case yang ada pada diagram use case.

\section{METODE REKAYASA PERANGKAT LUNAK}

Pada penelitian ini menggunakan diagram-diagram UML.

\subsection{Diagram High Level Class}

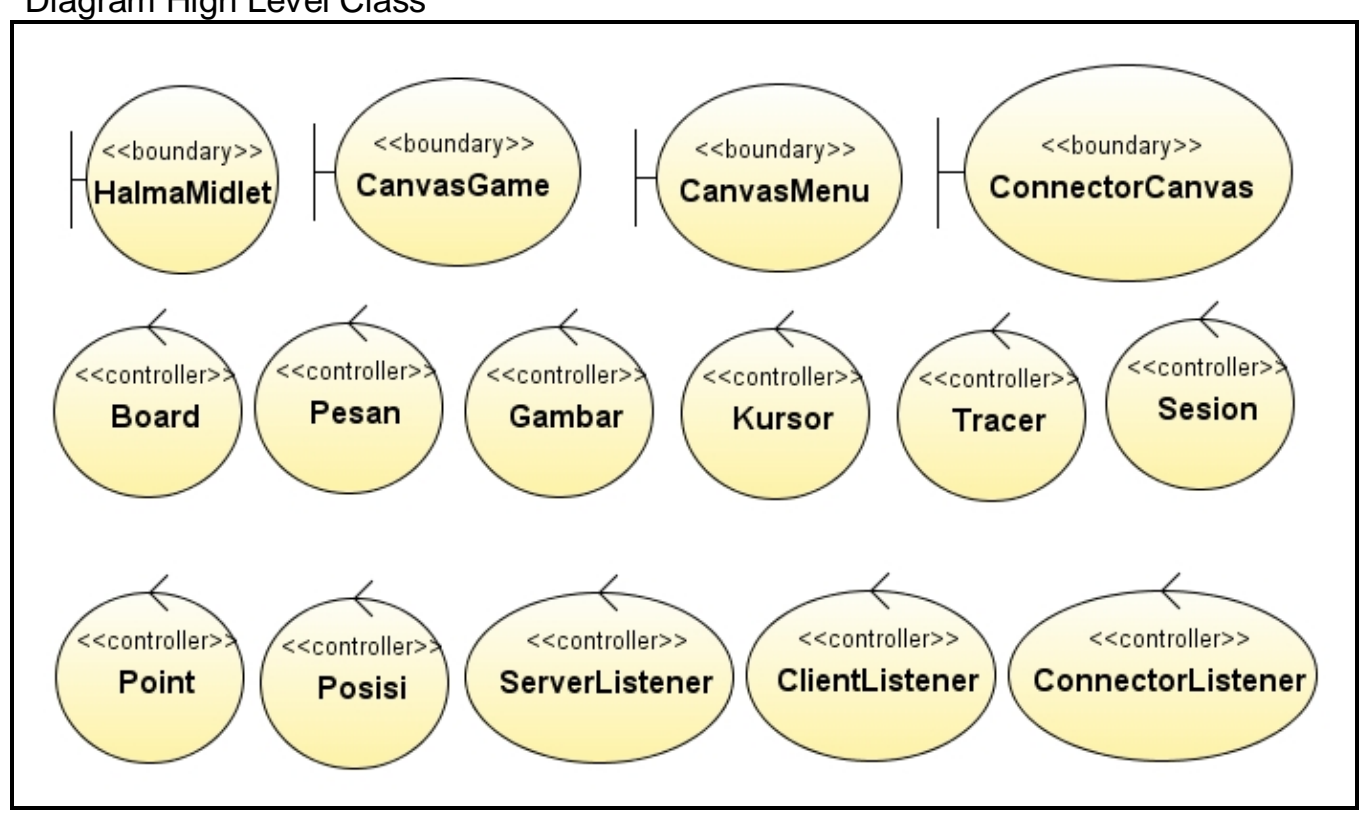

Gambar 3.1 Diagram High Level Class Aplikasi Game Halma Multiplayer

\subsection{Diagram Use Case}

Diagram Use case terdapat satu actor yaitu pengguna yang dapat berlaku sebagai client atau pun server. Sebagai server pengguna akan berinteraksi dengan empat Use case dalam aplikasi ini yaitu membuat permainan baru, melihat petunjuk permainan, melihat tentang program, keluar aplikasi. 


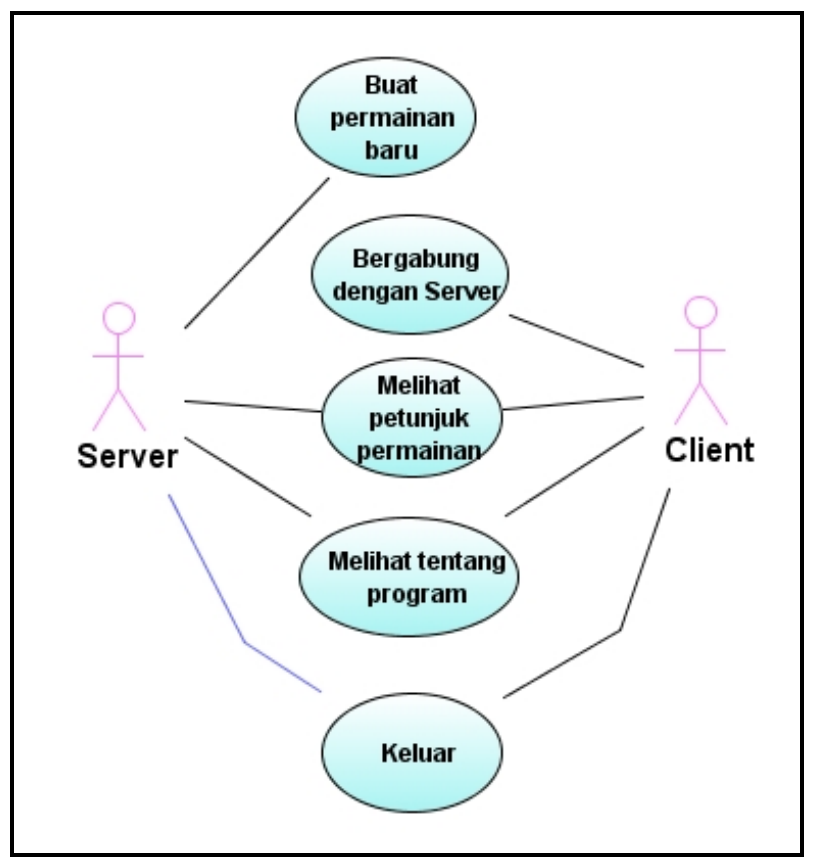

Gambar 3.2 Diagram Use case Aplikasi Game Halma Multiplayer

\subsection{Diagram Class}

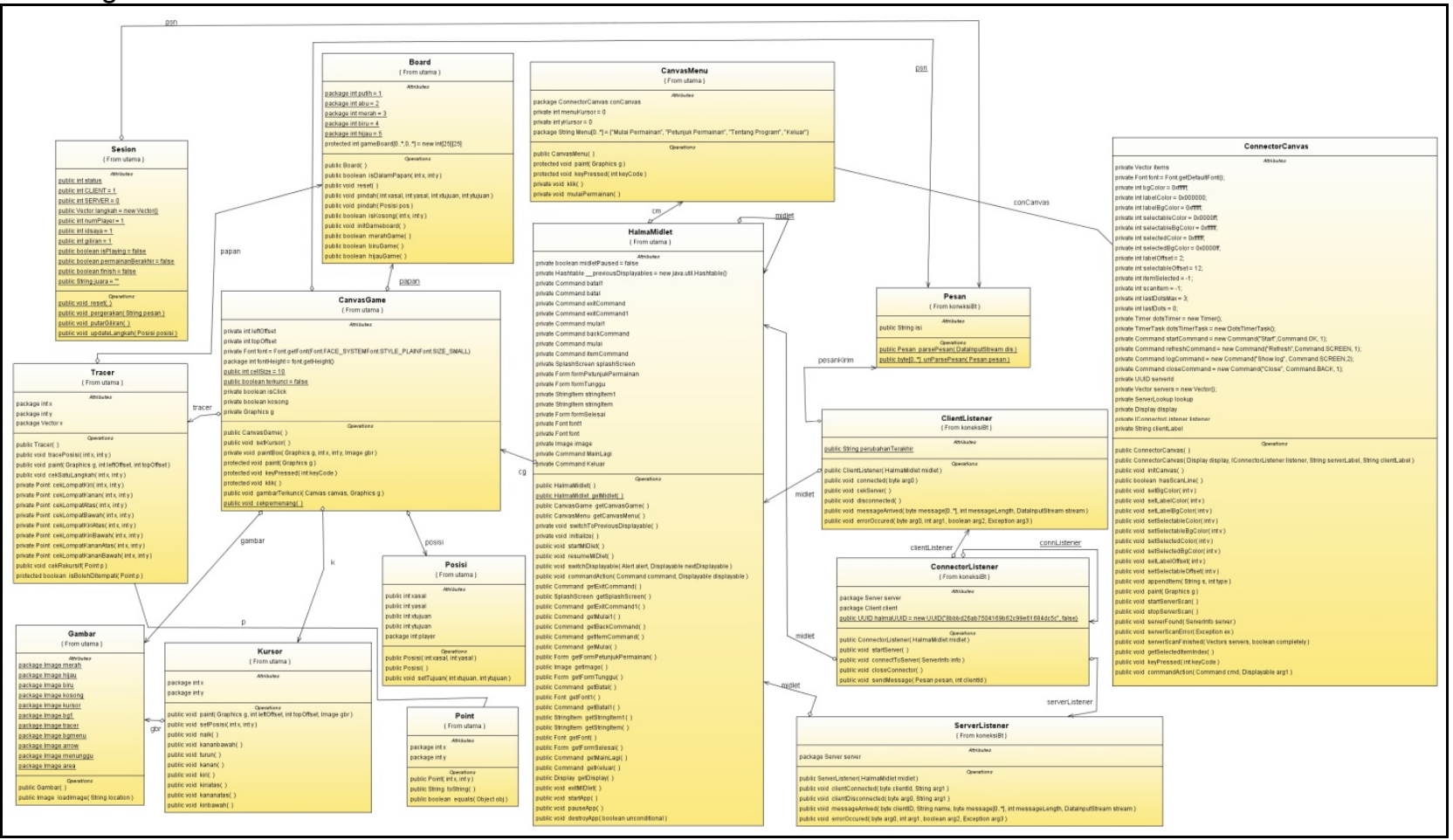

Gambar 3.3 Diagram Class Game Halma Multiplayer

3.4 Diagram Sequence

Terdapat lima diagram sequence dalam aplikasi ini. 
TELEMATIKA

3.4.1 Diagram Sequence Buat Permainan Baru

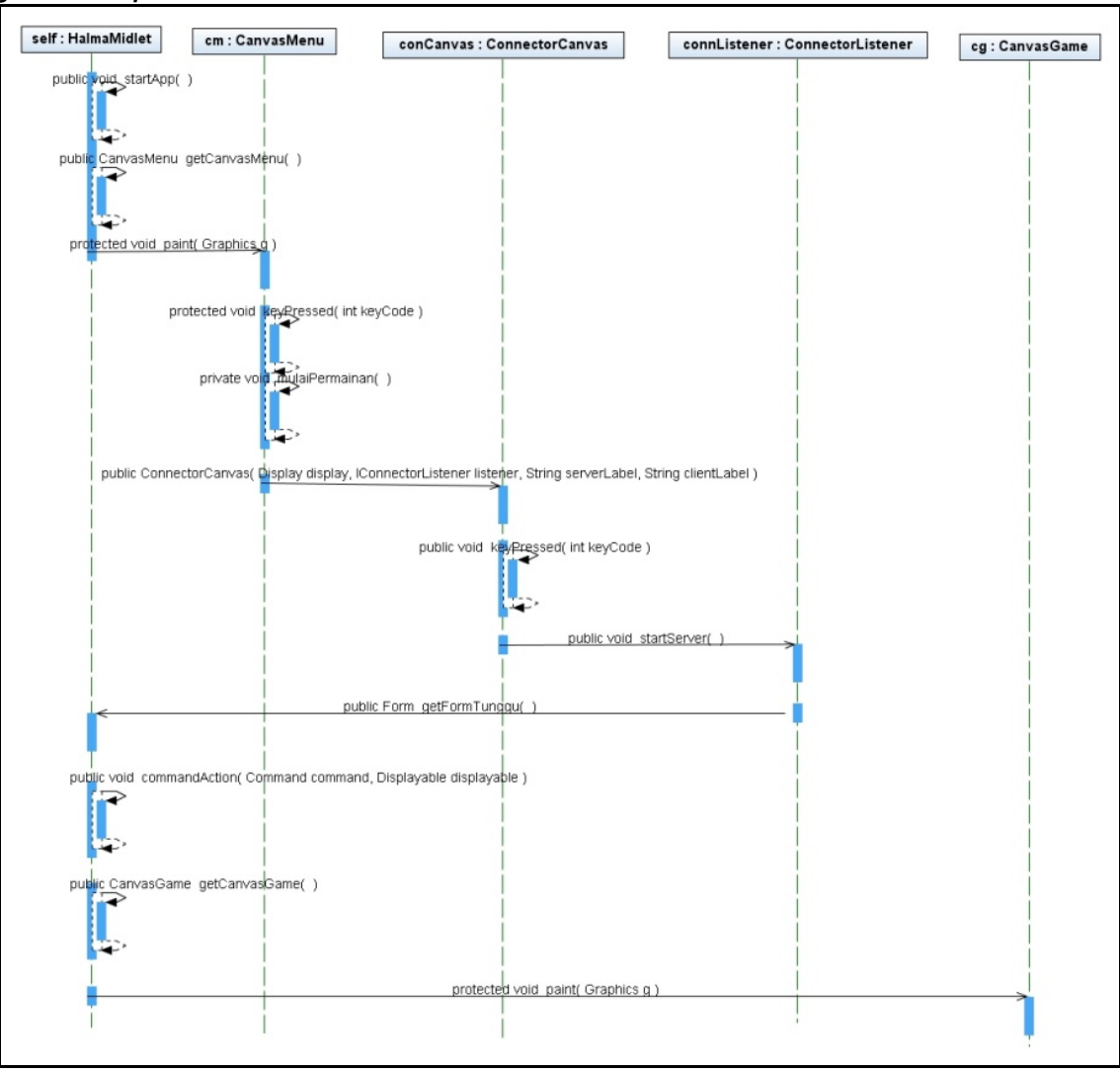

Gambar 3.4 Diagram Sequence Buat Permainan Baru

3.4.2 Diagram Sequence Memilih Menu Bergabung Dengan Server

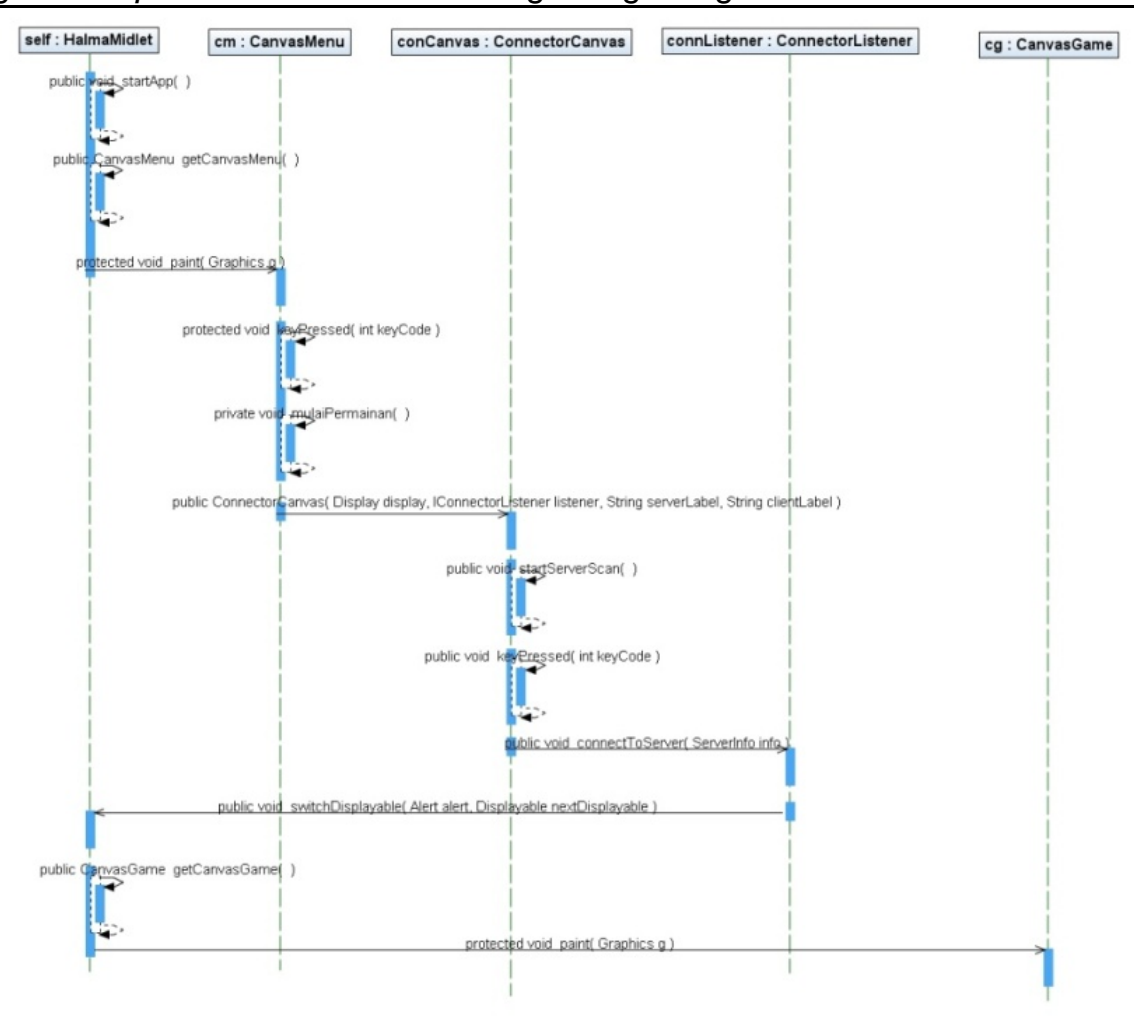

Gambar 3.5 Diagram Sequence Bergabung Dengan Server 
3.4.3 Diagram sequence Melihat Petunjuk Permainan

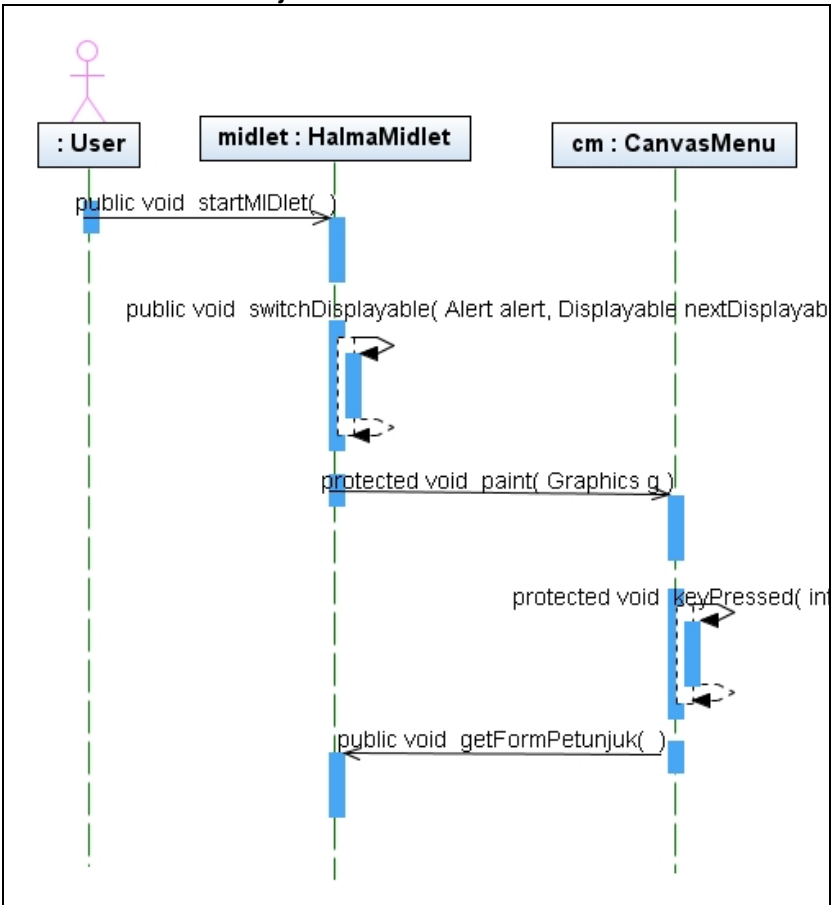

Gambar 3.6 Diagram Sequence Melihat Petunjuk Permainan

3.4.4 Diagram Sequence Melihat Tentang Program

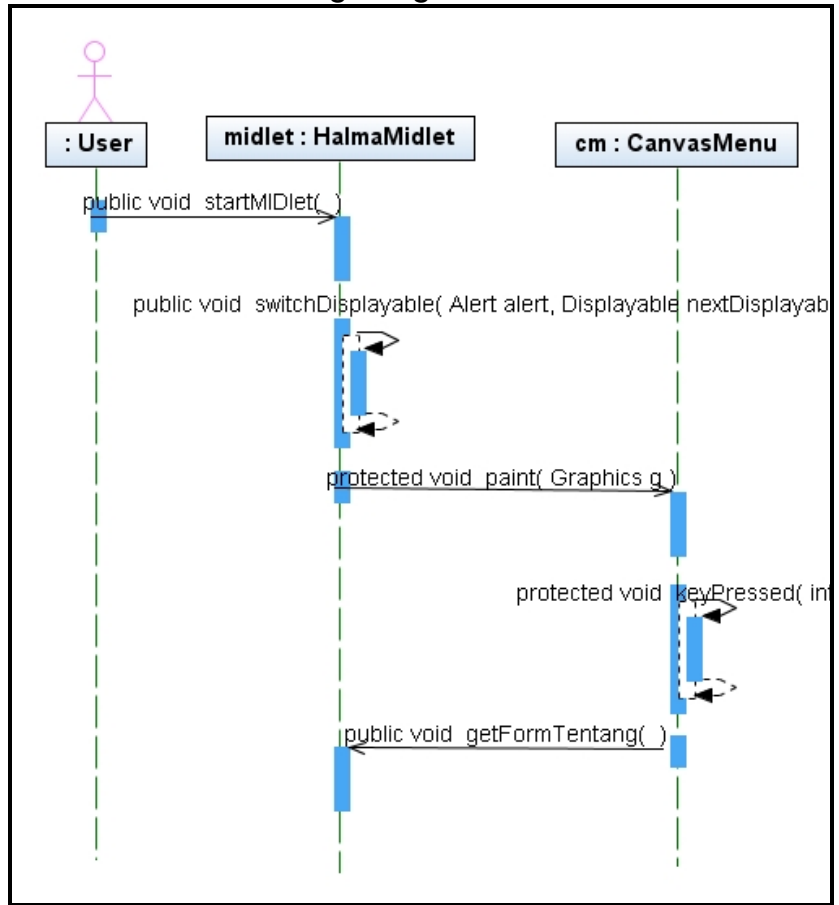

Gambar 3.7 Diagram Sequence Melihat Tentang Program

3.4.5 Diagram Sequence Keluar Aplikasi 


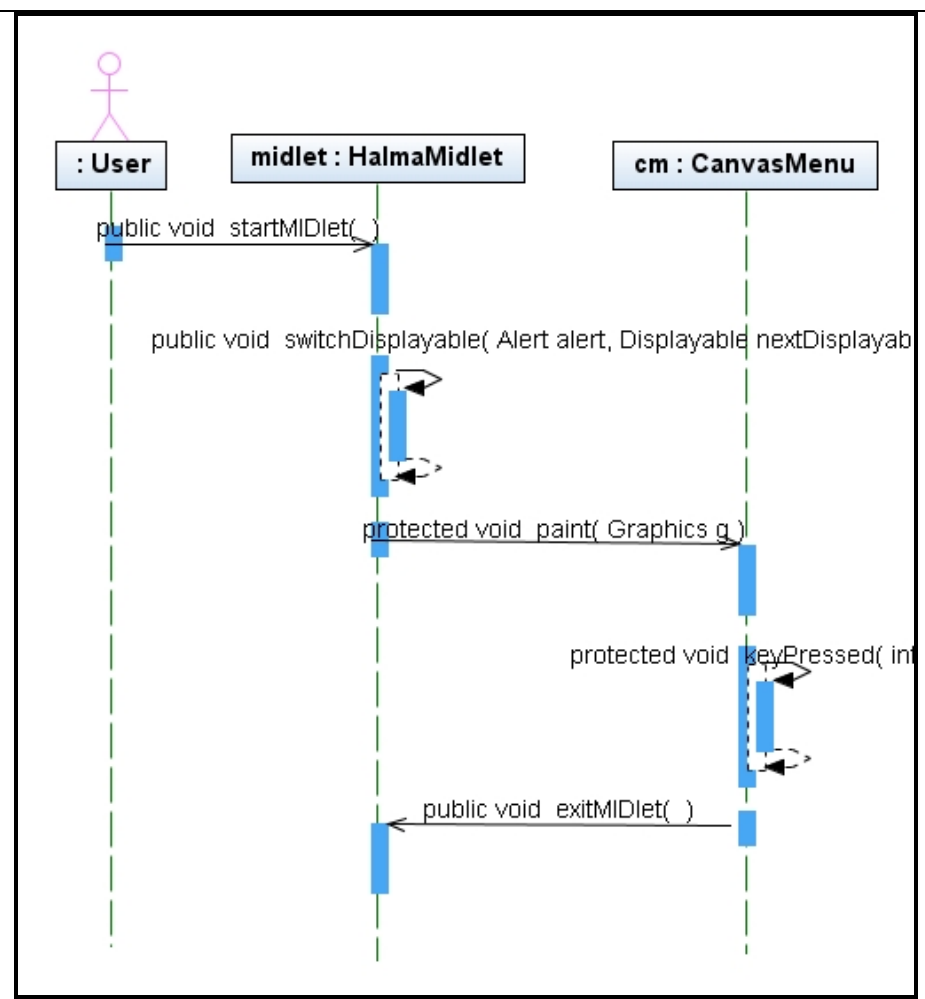

Gambar 3.8 Diagram Sequence keluar aplikasi

\subsection{Diagram Activity}

Dalam diagram dibawah ini menunjukkan aktivitas pengguna ketika bermain halma.

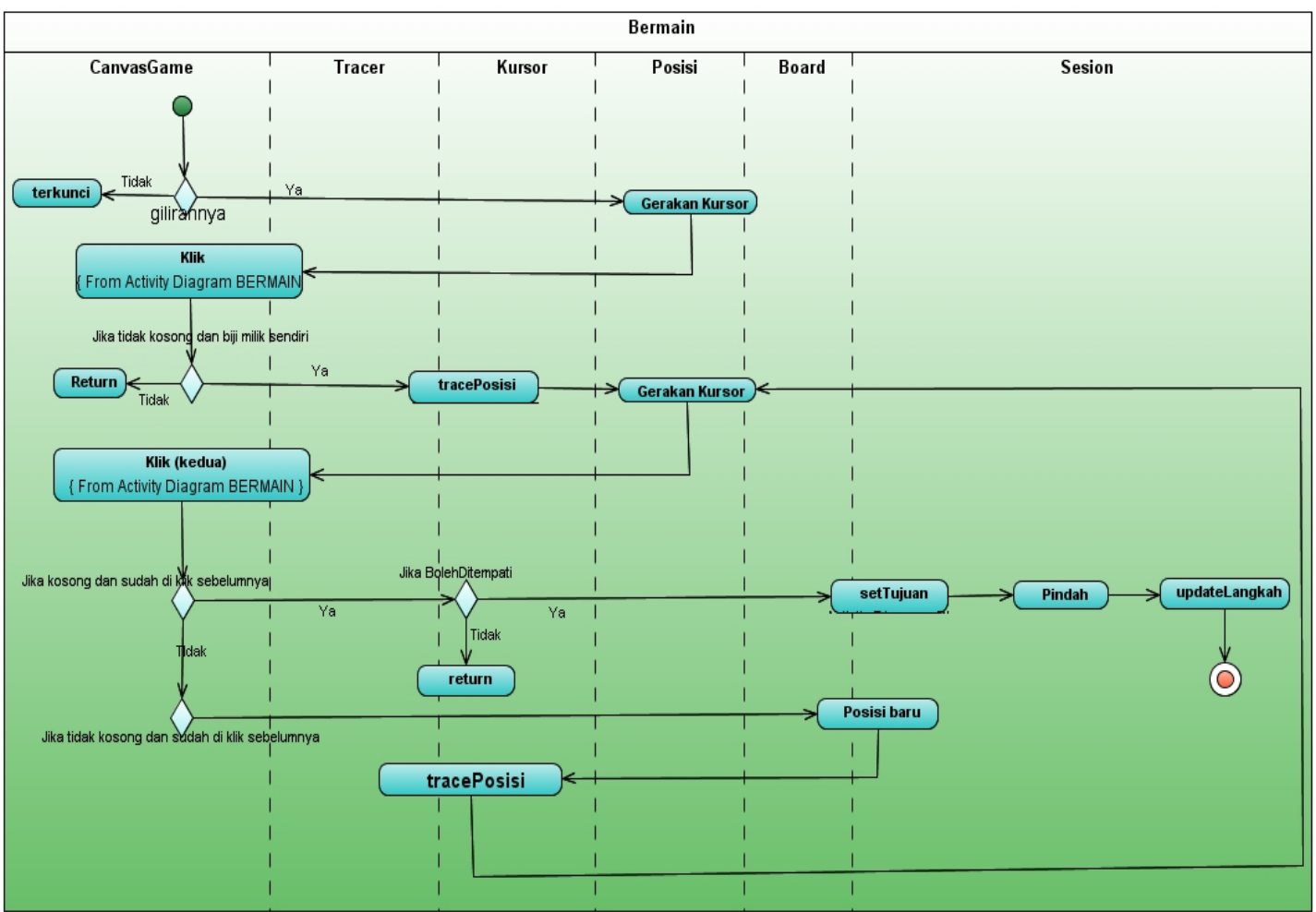

Gambar 3.9 Diagram Activity Bermain 


\section{HASIL DAN PEMBAHASAN}

4.4 Implementasi pada Netbeans 6.1

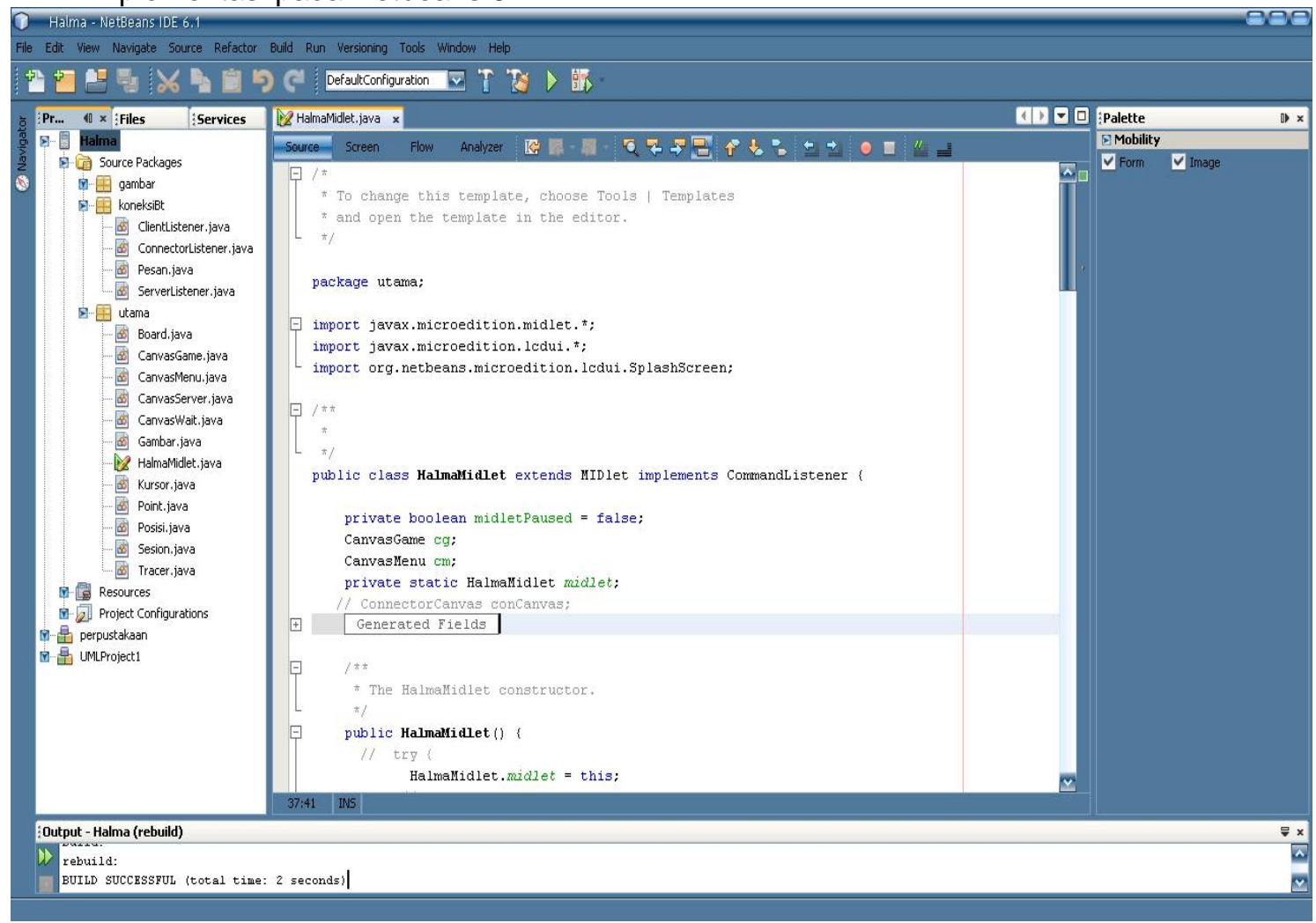

Gambar 4.1 Tampilan pada NetBeans 6.1

\subsection{Kelas-kelas pada program}

Tahap development dilakukan pengembangan dan perbaikan constructor, method, dan class, agar dapat menghasilkan sistem seperti yang diinginkan. Terdapat 15 kelas yang berperan dalam program. Kelas HalmaMidlet sebagai kelas utama program. Kelas CanvasMenu untuk menampilkan menu utama. Kelas Board, CanvasGame, Kursor, Point, Posisi, Sesion, dan Tracer sebagai kelas yang berperan saat permainan berlangsung. Kelas Gambar untuk instansiasi gambar. Kelas ConnectorCanvas adalah kelas dari dalam framework yang berfungsi untuk mengatur koneksi awal client-server. Dan kelas ConnectorListener, ClientListener, ServerListener, Pesan digunakan untuk penanganan koneksi serta komunikasi pada server dan client.

4.6 Implementasi Antarmuka pada Handphone

Tahap deployment merupakan tahap terakhir pada metodologi GRAPPLE. Seluruh source code yang telah disusun mulai dari tahap perancangan hingga development diintegrasikan dengan handphone, sehingga seluruh tampilan sistem dapat tampil dan digunakan oleh user. 


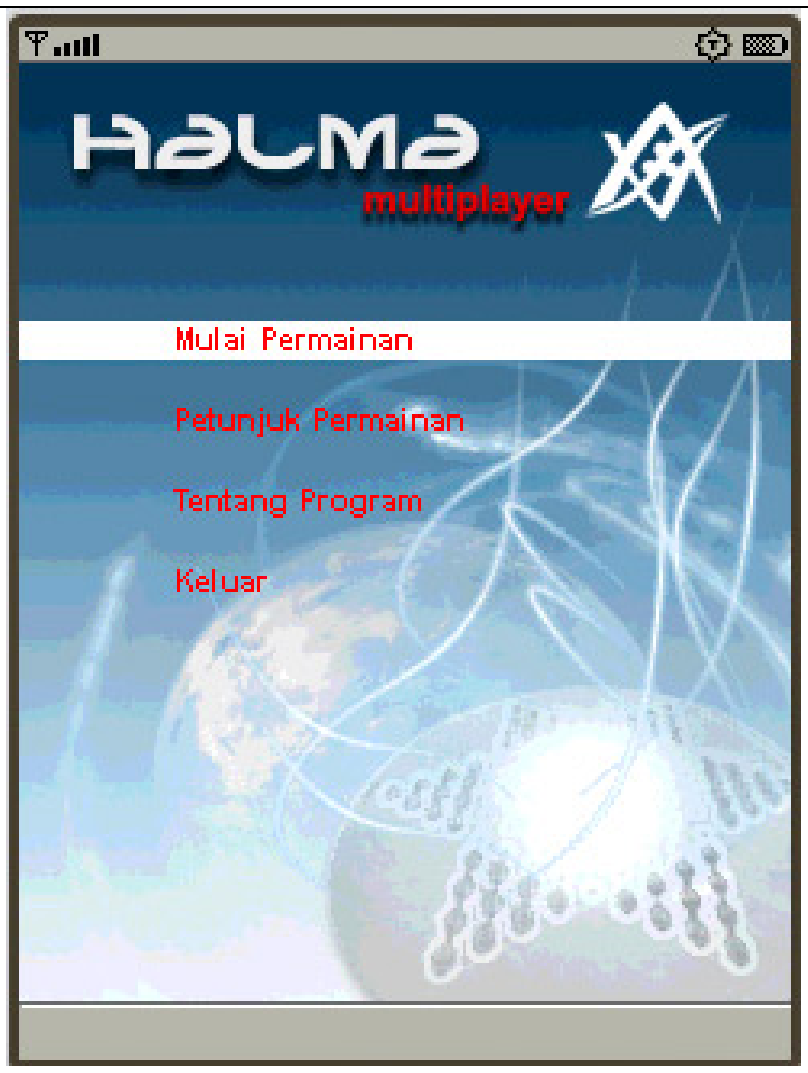

Gambar 4.2 Tampilan pada menu utama

\section{Finll}

쥥 죠

Buat Server:

MirelessToolkit

Bergabung:

Mencari...

Menu

1 Cari Seruer

2 Baru 
Gambar 4.3 Tampilan pada awal koneksi clien-server

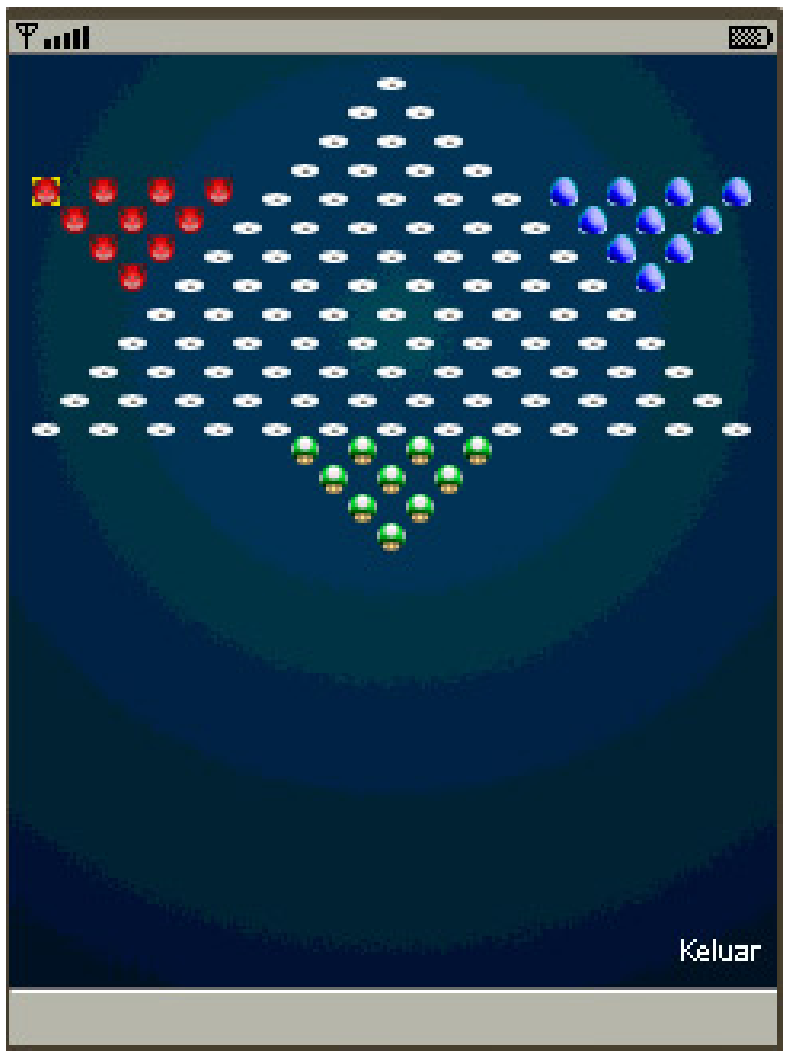

Gambar 4.4 Tampilan papan permainan

\section{KESIMPULAN}

Kesimpulan yang dapat diambil:

1. Telah berhasil dibangun sebuah Mobile Game Handphone multiplayer menggunakan media Bluetooth.

2. Aplikasi J2ME dapat menggunakan Bluetooth sebagai koneksi, dan memungkinkan dibuat server-client dengan jumlah client yang terkoneksi bisa lebih dari dua (hanya peer-to-peer).

\section{DAFTAR PUSTAKA}

Aditya, Antonius, 2004, Pemrograman Mobile Java dengan MIDP 2.0 Andi, Yogyakarta. Budi Raharjo dkk., April 2007, Tuntunan Pemrograman Untuk Handphone, Bandung. Klingsheim, Andre N., Juni 2004, J2ME Bluetooth Programming, Bergen : Department of Informatics University of Bergen

Munawar, 2005, Pemodelan Visual dengan UML, Penerbit Graha Ilmu, Yogyakarta.

Schmuller, Joseph, 1999, Teach Yourself UML in 24 Hours, Sam Publishing, Indianapolis.

Setianto Lukas, 2006, Prototype Efisiensi Sistem Parkir Karyawan Menggunakan Media Bluetooth, Universitas Kristen Petra : Jurusan Teknik Elektro. 